\title{
Isıl İşlemin Akımsız Ni-B/Ni-B-W Dubleks Kaplamanın Korozyon Direncine Etkisinin Analiz Edilmesi
}

\author{
Gökçe Dil ${ }^{1}$, Ali Gökşenli2 ${ }^{2}$, Behiye Yüksel ${ }^{3}$, Faiz Muhaffel ${ }^{4}$ \\ Geliş / Received: 08/04/2020 \\ Revize / Revised: 06/09/2020 \\ Kabul / Accepted: 07/09/2020
}

\section{$\overline{\mathbf{O Z Z}}$}

Bu çalışmada çelik malzemenin yüzeyi, akımsız kaplama yöntemi ile Ni-B/Ni-B-W ile kaplanmış, kaplamaların içyapı ve korozyon direnci incelenmiştir. Ni-B/Ni-B-W kaplaması asidik hipofosfit ve alkalin borohidrid indirgeyici banyolarla akımsız olarak kaplanmıştır. Kimyasal bileşim analizi için EDS yöntemi kullanılmıştır. Tarayıcı Elektron Mikroskobu (SEM) ile kaplamanın kesit ve yüzey morfolojisi incelenmiştir. SEM analizi sonucu kaplamaların üniform olduğu, yüzeye çok iyi bir adezif bağ ile gözeneksiz bir şekilde bağlandığı ve kaplamaların birbirleriyle uyumlu olduğu gözlemlenmiştir. XRD analizleri sonucu her iki kaplamanın da amorf yapıda olduğu, $450{ }^{\circ} \mathrm{C}$ 'de bir saat uygulanan 1 sıl işlem ile kaplamanın kristalleştiği ve nikel borit $\left(\mathrm{Ni}_{2} \mathrm{~B}\right.$ ve $\left.\mathrm{Ni}_{3} \mathrm{~B}\right)$ çökeltilerinin oluştuğu tespit edilmiştir. Çelik, 1sıl işlem görmemiş ve görmüş Ni-B ve Ni-B/Ni-B-W kaplamaların korozif karakterini incelemek için 5\% $\mathrm{H}_{2} \mathrm{SO}_{4}$ çözeltide daldırma ve Potansiyometrik Polarizasyon deneyleri $(\% 3,5 \mathrm{NaCl}$ sulu çözeltide) gerçekleştirilmiştir. Deneyler sonucu her iki tür kaplamanın korozyon direncinin kaplanan malzeme olan çelikten daha yüksek olduğu görülmüştür. Isıl işlem görmemiş Ni-B/Ni-B-W kaplamasının korozyon direncinin Ni-B kaplamaya göre daha iyi olduğu gözlemlenmiştir. Isıl işlemin uygulanması sonucu her iki kaplamanın da korozyon direnci artmıştır. Ancak Ni-B/Ni-B-W dubleks kaplamasında artı̧̧ Ni-B kaplamaya göre daha fazladır. Kaplamaya tungstenin eklenmesi ile 1 sıl işlem sonrası yüzeyde oluşan koruyucu tungsten oksit tabakasından dolayı, kaplamanın korozyon direnci artırmıştır.

\footnotetext{
1iletişim: gdil@ford.com.tr (https://orcid.org/0000-0002-2036-4413)

Ford Otosan Ar-Ge Merkezi. İstanbul.

${ }^{2 *}$ Sorumlu yazar İletișim: goksenli@itu.edu.tr (https://orcid.org/0000-0002-1068-8705)

Makina Fakültesi, İstanbul Teknik Üniversitesi, 34437, İstanbul.

İletişim: behiyeyuksel@gmail.com (https://orcid.org/0000-0003-4645-6460)

Metalurji ve Malzeme Mühendislik Bölümü, İstanbul Gedik Üniversitesi, 34876, İstanbul.

4İletişim: muhaffel@itu.edu.tr (https://orcid.org/0000-0002-9814-7478)

Kimya ve Metalurji Mühendislik Bölümü İstanbul Teknik Üniversitesi, 34469, İstanbul.
} 


\title{
Analysis of the Effect of Heat Treatment on Corrosion Resistance of Electroless Ni-B/Ni-B-W Dublex Coating
}

\begin{abstract}
The present work deals with the formation of Ni-B/Ni-B-W duplex coatings on steel by electroless plating process and evaluation of their microstructure and corrosion resistance. The Ni-B/Ni-B-W duplex coatings were prepared using dual baths (alkaline borohydride- reduced electroless nickel baths) with Ni-B as inner layer. EDS analyses were carried out for chemical composition analyses. Scanning electron microscopy (SEM) of the cross-sectional view of the electroless nickel duplex coatings reveal that the coatings are uniform and the compatibility between the layers is good. Also the surface morphology was analysed to characterize the surface properties. Coatings were characterized using XRD. The study reveals that the Ni-B and Ni-B-W coatings are amorphous in their as-plated condition and upon heat treatment at $450^{\circ} \mathrm{C}$ for $1 \mathrm{~h}$, both Ni-B and Ni-B-W coatings crystallize and produce nickel and nickel borides $\left(\mathrm{Ni}_{2} \mathrm{~B}\right.$ ve $\left.\mathrm{Ni}_{3} \mathrm{~B}\right)$ in the respective coatings. Polarization tests (in 3,5\% $\mathrm{NaCl}$ aqueous solution) and immersion tests (in 5\% $\mathrm{H}_{2} \mathrm{SO}_{4}$ solutions) were carried out to analyse the corrosion properties. The tests were applied on substrate steel, as-plated and heat treated Ni-B and Ni-B/Ni-B-W coatings and were compared with each other. According to the results, all coatings performed better corrosion resistance (CR) than the substrate steel. As-plated Ni-B/Ni-B-W coatings demonstrated better CR than Ni-B coatings. By applying heat treatment, corrosion characteristics improved in both Ni-B and Ni-B/Ni-B-W coatings but much more improvement was observed by Ni-B/Ni-B-W coatings. Adding tungsten to the coating improved additionally the $\mathrm{CR}$ due to the formation of protective tungsten oxide layer.
\end{abstract}




\section{GIRIŞ}

Genel tanım olarak akımsız kaplama; bir kimyasal kaplama yöntemi olup, herhangi bir elektrik akım kaynağı kullanmadan, çözelti içindeki metallerin yüzeyde biriktirilmesidir [1] En yaygın olarak kullanılan kaplama malzemesi nikeldir. Çözelti, metal tuzu, nikel iyonunun indirgenmesi için redükleyici ajan, karmaşık elemanlardan, stabilizatörden, hızlandırıcı, frenleyiciler, $\mathrm{pH}$ ayarlayıcılar ve ıslatabilirlik ajanlarından oluşmaktadır. Nikel tuzları içeren bir çözeltiye daldırılmış olan ve kaplanmasını istediğimiz malzeme, çözelti içinde bulunan redükleyicilerin etkisi ile nikel iyonlarının nikel metaline redüklenmesi reaksiyonu sonucu yüzeyde bir kaplama oluşturmasına "Akımsız nikel kaplama" denmektedir [2]. Redükleme esnasında açığa çıkan bor ile reaksiona girip birleşen nikel bir nikel alaşımı meydana getirir. Meydana gelen bu redüklenme, katalitik karakter gösteren nikel üzerinde devam ederek kaplamanın birikip kalınlaşmasına neden olmaktadır. Oluşan şeklinden dolayı bu tip kaplamalara aynı zamanda "Otokatalitik Kaplamalar" da denmektedir. Akımsız kaplama yöntemi 1946'da Brenner ve Riddell tarafindan geliştirilmiştir. [3]. Günümüzde akımsız nikel kaplamaları makina, otomotiv, uçak-uzay, kimya, elektronik, gıda, bilgisayar gibi farklı sektörlerde yaygın olarak kullanılmaktadır. [46]. Akımsız nikel kaplamaların en önemli avantajı, parça geometrisinden bağımsız olarak yüzeyi aynı kalınlıkta ve homojen bir şekilde kaplayabilmesidir. [7]. Diğer avantajları ise; yüksek korozyon direnci, metal ve plastik seramik gibi metal olmayan malzemelerin de kaplanması, kaynak ve lehime uygunluğu, yüksek sertlik ve aşınma direncine sahip olmakla birlikte sertlik değerlerin ısıl işlemle arttırılabilmesidir [8-10]. Bu avantajlarından dolayı günümüzde krom kaplamalarına alternatif olarak da kullanılmaktadır. Dezavantajları ise kaplamanın gevrek karakterde olması, akımlı kaplama yöntemlerine göre sürecin daha yavaş olması, kaplama karakterinin çözelti ve kaplama süreç parametrelerinin değişiminden oldukça etkilenmesinden dolayı kaplamanın çok kontrollü yapılması gerekliliği. Kaplamada kullanılan redükleyici türüne bağlı olarak Ni-P veya Ni-B kaplamaları elde edilmektedir. Ni-P kaplamaları yüksek korozyon direnç ve kaynak-lehimleme kapasitesine sahiptir [11-15]. Ni-B kaplamaları ise yüksek sertlik ve gelişmiş tribolojik özelliklere sahiptir. Ni-B kaplamaların özelliklerini geliştirmek için farklı yöntemler kullanılmışır [16-19]. Kaplamaya bakır, tungsten, kobalt, molibden gibi ikinci bir metalin (M) eklenmesiyle Ni-B-M şeklinde kaplamaların oluşturulması bir alternatiftir [20-24]. Diğer bir yöntem ise kaplamaların içine WC, SiC, BN gibi farklı sert seramik parçacıkların ilave edilerek özellikle kaplamaların tribolojik özellikleri geliştirilmiştir [25-28]. Alternatif çözümler arasında üst üste çoklu kaplamalar yer almaktadır [29-32]. Bu tip kaplamalarda Ni-P ve Ni-B gibi iki veya üç farklı nikel alaşımlı kaplamalar oluşturulmaktadır [33]. Nikel kaplamaları amorf bir yapıya sahiptir, ancak uygulanan ısıl işlem ile kristalik bir yapı oluşmaktadır. Kristal yapı nedeniyle kaplamanın tribolojik ve korozif özellikleri değişmektedir [34,35]. Çoklu katmanlı kaplamaların avantajları, malzemenin sertlik ve aşınma direnç özelliklerinin iyileştirmesidir. Özellikle uygulanan ısıl işlem ile kristal yapıdaki kaplamaların tribolojik özelliklerinde artış tespit edilmiştir [33]. Dubleks kaplamanın diğer avantajı ise her bir kaplamanın farklı korozyon potansiyel değerine sahip olmasından dolayı katodik koruma yöntemiyle korozyon direncinin artmasıdır [32]. Dubleks kaplamaların korozif özellikleri literatürde incelenmiş

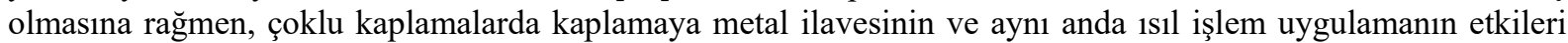
fazla incelenmemiştir. Bu çalışmada çelik malzeme üzerine akımsız Ni-B/Ni-B-W dubleks kaplaması üzerinde oluşturulacaktır. İlave metal olarak tungstenin tercih edilmesinin nedeni, üstün aşınma direnci ve korozif direnç özelliği göstermesidir [36-39]. Tungsten ilavesi ve uygulanan ısıl işlem ile kaplama yüzeyinde korozyon direncini arttıran yoğun tungstenoksit tabakası oluşmaktadır [40,41]. Oluşturulan tungsten metal takviyeli Ni-B/Ni-B-W dubleks katmanlı kaplamaya ısıl işlem uygulanarak ısıl işlemin içyapı, yüzey morfolojisi ve korozyon direnç özellikleri açısından analiz edilecek, çelik ve Ni-B kaplaması ile karşılaştırılacaktır.

\section{DENEYSEL YÖNTEMLER}

Deney numunesi olarak 20x70x4 ve 20x40x4 mm boyutlarında basit karbonlu test numuneleri hazırlanmıştır. Deney numunesi kademeli olarak kabadan inceye doğru (1200) parlatılmış, trikloretilende daldırdıktan sonra ultrasonik banyoda $70{ }^{\circ} \mathrm{C}$ de deterjan ile temizlenmiştir. Numuneler daha sonra $\% 30$ luk $\mathrm{HCl}$ çözeltiye iki dakikalığına daldırılmış ve akabinde damıtılıış su ile durulanmıştır. Ön hazırlama işlemlerinden hemen sonra akımsız kaplama işlemlerine başlanmıştır. Çalışmamızda yeni bir formülasyon kullanılmıştır. Çözeltilerde yüksek çözünürlüğe sahip ve kararlı yapısından dolayı sodyum borohidrid, stabilizatör olarak da kurşun tungstat $\left(\mathrm{PbWO}_{4}\right)$ kullanılmıştır. $\mathrm{PbWO}_{4}$, talyum nitrat gibi çevresel problemler oluşturmamaktadır. Çözelti pH değerinin 13,5 da olmasını sağlamak amacıyla potasyum hidroksit tercih edilmiştir. Çözeltide nikel iyonlarını elde edebilmek için herhangi bir çözülebilen tuz kullanılabilirken, nikel klorid anyonların kaplama çözeltisindeki diğer bileşenlerden daha inert olması nedeniyle tercih edilmiştir. Nikel hidroksitin çökelmesini 


\begin{tabular}{|c|c|c|}
\hline & $\begin{array}{l}\text { BŞEÜ Fen Bilimleri Dergisi } \\
7(2), 911-922,2020\end{array}$ & $\begin{array}{r}\text { BSEU Journal of Science } \\
\text { DOI: } 10.35193 / \text { bseufbd. } 716170\end{array}$ \\
\hline VERSI & & 58-7575 (http://dergipark.gov.tr/bseufbd) \\
\hline
\end{tabular}

önlemek amacıyla etilendiamin çözeltiye eklenmiştir. NiB/Ni-B-W dubleks kaplamasını oluşturmak için banyo kaplama bileşenleri ve çalışma şartları tablo 1 de görülmektedir.

Tablo 1. Akımsız NiB/Ni-B-W kaplaması için çözeltinin bileşenleri ve çalışma ortamı

\begin{tabular}{|c|c|c|}
\hline & Bileşen & Çalışma ortamı \\
\hline \multirow{3}{*}{ Ana solüsyon } & $\mathrm{NiCl}_{2} \quad 24 \mathrm{~g} / 1$ & \multirow{9}{*}{$\begin{array}{l}\text { ph } 13,5 \pm 0,2 \\
\text { Sicaklık } 90 \pm 2{ }^{\circ} \mathrm{C} \\
\text { Süre } 2 \text { saat }\end{array}$} \\
\hline & $\mathrm{EDA} \quad 60 \mathrm{ml} / \mathrm{l}$ & \\
\hline & $\mathrm{KOH} \quad 26,5 \mathrm{~g} / 1$ & \\
\hline \multirow[t]{2}{*}{ İndirgeyici solüsyonu } & $\mathrm{Na}_{2} \mathrm{WO}_{4} * 2 \mathrm{H}_{2} \mathrm{O} \quad 40 \mathrm{~g} / \mathrm{l}$ & \\
\hline & $\mathrm{NaBH}_{4} 120 \mathrm{~g} / \mathrm{l}$ & \\
\hline \multirow{4}{*}{ Stabilizatör (Dengeleyici) solüsyonu } & $\mathrm{NaOH} \quad 263 \mathrm{~g} / \mathrm{l}$ & \\
\hline & $\mathrm{PbWO}_{4} \quad 2,6 \mathrm{~g} / \mathrm{l}$ & \\
\hline & $\mathrm{EDA} \quad 40 \mathrm{ml} / 1$ & \\
\hline & EDTA $13 \mathrm{ml} / 1$ & \\
\hline
\end{tabular}

Çözeltinin hazırlanmasında manyetik karıştırıcı kullanılmıştır. Test numunelerinin banyoya daldırılmasından sonra her 30 dakikada bir çözeltiye 2,6 ml stabilizatör ve 2,6 ml de indirgeyici bileşenleri eklenmiştir [23]. NiB/Ni-B-W dubleks kaplamalarının bir kısmına daha sonra ısıll işlem uygulanmıştır. Isıl işlemde numuneler atmosferik çalışma şartlarında fırında bir saat boyunca $450{ }^{\circ} \mathrm{C}$ sıcaklıkta bir saat tutulmuştur. NiB/NiB-W kaplamasının yüzey morfolojisi ve kesit yapısını incelemek amacıyla tarayıcı elektron mikroskop (SEM JSM-5310, Japan Electronics) tercih edilmiştir. Kaplamanın ısıl işlemsiz ve 1 șll işlem sonrası $\left(450{ }^{\circ} \mathrm{C}\right.$ de bir saat) yapısını incelemek için X-ışın difraksiyonu (XRD - Rigaku Dymax, Japonya, $\mathrm{Cu} \mathrm{K} \alpha$ radyasyon $(\alpha=0.154178$ $\mathrm{nm}$ ) ve $50 \mathrm{kV}$ and 300mA'lik monokromatör ve 4\% dak lık tarama hızıyla) kullanılmıştır. Kaplamadaki W miktarını tespit edebilmek için, Enerji Dağılım Spektrometre (EDS) analizi kullanılmıştır. Kaplamanın korozyon direncini incelemek amacıyla polarizasyon ve daldırma deneyleri gerçekleştirilmiştir. Daldırma deneylerinde çelik, Ni-B ve $\mathrm{NiB} / \mathrm{Ni}-\mathrm{B}-\mathrm{W}$ kaplamaları $\% 5 \mathrm{H}_{2} \mathrm{SO}_{4}$ çözeltisine daldırılmış ve 7 gün boyunca her gün hassas terazide tartılarak kütle kaybı tespit edilmiştir. Korozyon direncini tespit etmek için elektrokimyasal korozyon testi uygulanmıştır. Numunelere ait elektrokimyasal ölçümler Radiometer marka VoltaLab40 model elektrokimyasal analizör kullanılarak yapılmıştır. Bu amaçla yapılan deneyler ağ. \%3.5 NaCl sulu çözeltisi içinde üç elektrotlu (karşıt elektrot olarak grafit, referans elektrot olarak ise doymuş kalomel elektrot) hücrede oda sıcaklığında gerçekleştirilmiştir. Çalışma elektrodu olarak kullanılan çelik, ssıl işlem görmüş ve görmemiş $\mathrm{NiB}$ ve $\mathrm{NiB} / \mathrm{NiBW}$ kaplanmış numuneler, çalışma alanı $1 \mathrm{~cm}^{2}$ olacak şekilde epoksi reçine ile kaplanmıştır. Potansiyodinamik eğrilerin elde edilebilmesi için seçilen tarama hızı ise $1 \mathrm{mV} / \mathrm{s}$ olmuştur.

\section{DENEYLER VE ANALIZZLER}

\section{A. Iç Yapı ve Yüzey Analizleri}

EDS analizi sonucu kaplamada ağırlıkça \%0,62 tungstenin (W) varlığı tespit edilmiştir (şekil 1). NiB/NiB-W dubleks kaplamalarının içyapı analizini gerçekleştirmek amacıyla ısıl işlem görmemiş ve $450{ }^{\circ} \mathrm{C}$ de 1 saat 1sıl işlem görmüş numunelere XRD analizi gerçekleştirilmiştir (şekil 2).

Isıl işlem görmemiş kaplamada (şekil 2 , b) sadece $2 \Phi=44.8^{\mathrm{O}}$ de bir pike rastlanmıştır ki bu da yüzey merkezli kübik yapıya sahip nikel fazının (llll 111$)$ düzlemine karşılık gelmektedir. Ancak genel yapı olarak kaplama amorf bir yapıya sahiptir. Isıl işlem görmüş kaplamada (şekil 2, a) ise nikel borid $\left(\mathrm{Ni}_{2} \mathrm{~B}\right.$ ve $\left.\mathrm{Ni}_{3} \mathrm{~B}\right)$ nanokristal nikel fazlarının oluşumu görülmektedir. $\mathrm{Ni}_{2} \mathrm{~B}$ bileşeni az miktarda tespit edilmiştir. Bunun nedeni ise yarı kararlı $\mathrm{Ni}_{2} \mathrm{~B}$ bileşeninin yükssek sıcaklıkta daha kararlı bir $\mathrm{Ni}_{3} \mathrm{~B}$ yapıya dönüşmesidir. Benzer bulgular Krishnaveni tarafından da tespit edilmişstir [13,33]. 


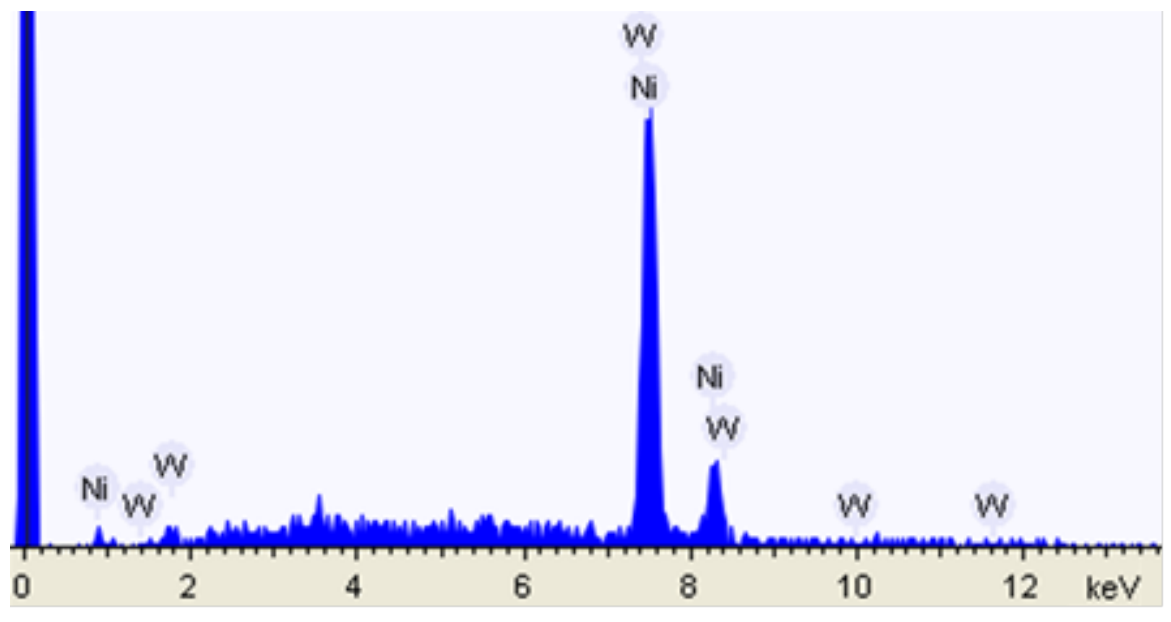

Şekil 1. EDS analizi

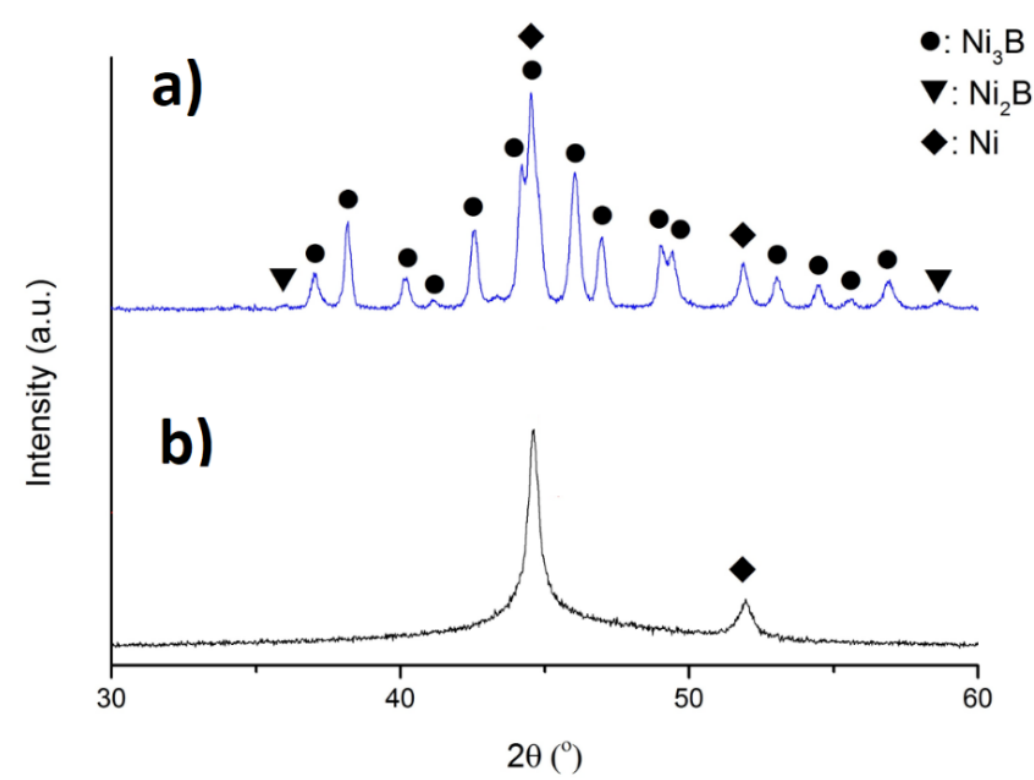

Şekil 2. $450^{\circ} \mathrm{C}$ de 1 saat 1 sıl işlem görmüş (a) ve $1 s 1$ işlem görmemiş (b) numunelerin XRD analiz sonuçları

Şekil 3 de 1 sıl işlem görmemiş (a), $450{ }^{\circ} \mathrm{C}$ de 1 saat 1 șl işlem sonrası kaplamanın yüzey morfolojisi (b) ve dubleks kaplamanın kesit görüntüsü (c) görülmektedir. Şekil 3 a ve b de yüzeyde, Ni-B kaplamalarında gözlemlenen tipik bir "Karnıbaharımsı" görüntü tespit edilmiştir. Şekil 3 b de küresel yumrucuk yapı olarak görülen şekiller, kristalleşmiş nikel ve nikel borid $\left(\mathrm{Ni}_{2} \mathrm{~B}\right.$ ve $\left.\mathrm{Ni}_{3} \mathrm{~B}\right)$ yapılarıdır. Kesit görüntüsü incelemesi sonucu $10,6 \mu \mathrm{m}$ lik Ni-B ve 4,8 $\mu \mathrm{m}$ lik Ni-B-W olmak üzere toplam 15,4 $1 \mu \mathrm{m}$ lik dubleks kaplamanın oluştuğu tespit edilmiştir. Ni-B kaplamanın çelik zemin malzemesine gözeneksiz bir şekilde adezif bağ meydana getirdiği görülmüş̧ür. 


\begin{tabular}{|c|c|c|}
\hline & $\begin{array}{l}\text { BŞEÜ Fen Bilimleri Dergisi } \\
7(2), 911-922,2020\end{array}$ & $\begin{array}{r}\text { BSEU Journal of Science } \\
\text { DOI: } 10.35193 / \text { bseufbd. } 716170\end{array}$ \\
\hline $\begin{array}{l}\text { BüECIISEYHEDEBALI } \\
\text { UNIVERSITESI }\end{array}$ & & 8-7575 (http://dergipark.gov.tr/bseufbd) \\
\hline
\end{tabular}
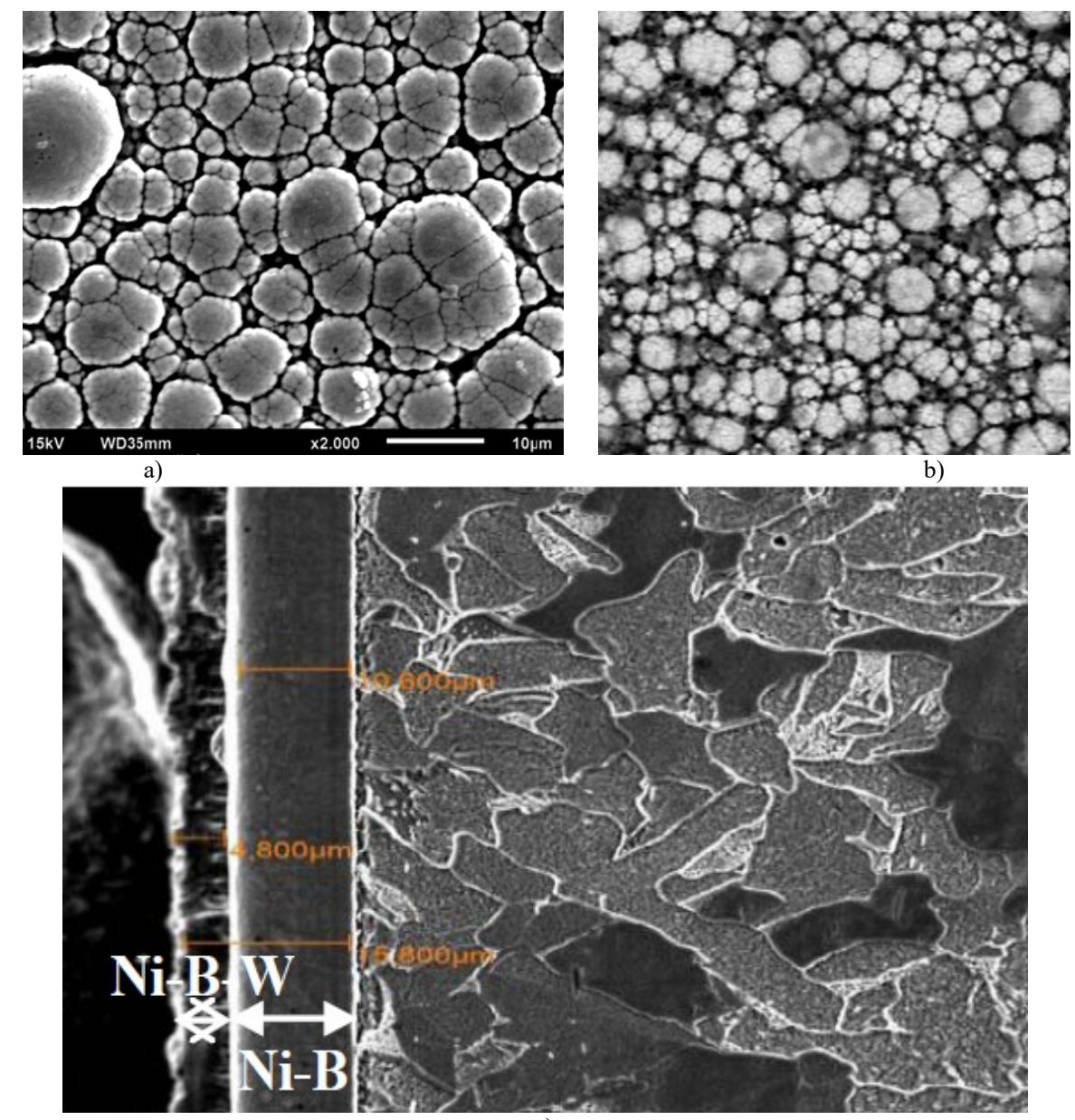

c)

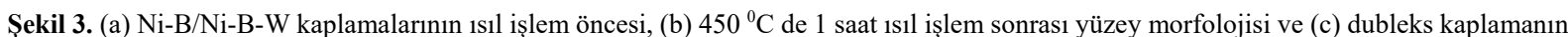
kesit görüntüsü

\section{B. Daldirma Deneyleri}

Daldırma deneyleri oda sıcaklığında $\% 5 \mathrm{H}_{2} \mathrm{SO}_{4}$ çözeltide gerçekleştirilmiştir. Her 24 saatte bir test numuneleri çözeltiden çıkartılıp, alkolle temizlenip kurutulduktan sonra hassas terazide tartılarak korozyon sonucu kütle kaybı tespit edilmiştir. Bu test yedi gün boyunca devam edilmiştir. Şekil 4 de Ni-B/Ni-B-W kaplaması kaplanan altlık malzeme olan çelik ile kütle kaybı açısından karşılaştırılmıştır. Görüldüğü gibi dubleks Ni-B/NiB-W kaplaması ile malzemenin korozyon direnci artmış oldu. Farklı kaplama türlerinin ve 1sıl işleminin (tavlamanın) korozyon direncine etkisini analiz edebilmek için ısıl işlem görmemiş ve görmüş Ni-B ve Ni-B/NiB-W dubleks kaplamaları $\% 5 \mathrm{H}_{2} \mathrm{SO}_{4}$ çözeltide bekletilmiş ve günlük kütle kaybı kaydedilmiştir (şekil 5). Şekil de de görüldüğü gibi tavlanmış Ni-B ve Ni-B/Ni-B-W kaplamaların korozyon direnci, ısıl işlem görmemiş kaplamalarına artmıştır. Ayrıca Ni-B/Ni-B-W dubleks kaplamaları Ni-B kaplamalarına göre daha yüksek korozyon direncine sahip olduğu tespit edilmiştir. 


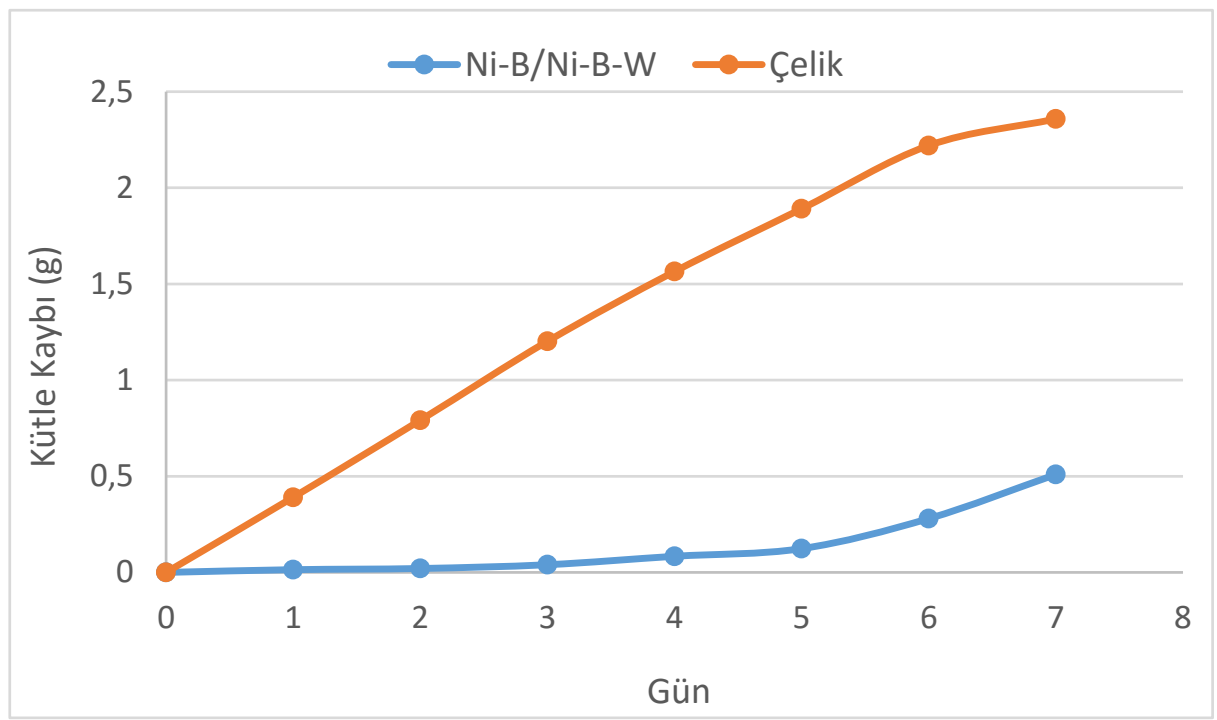

Şekil 4. Çelik ile Ni-B/Ni-B-W dubleks kaplamalarının $\% 5 \mathrm{H}_{2} \mathrm{SO}_{4}$ çözeltide bekletmede sonucu kütle kaybı

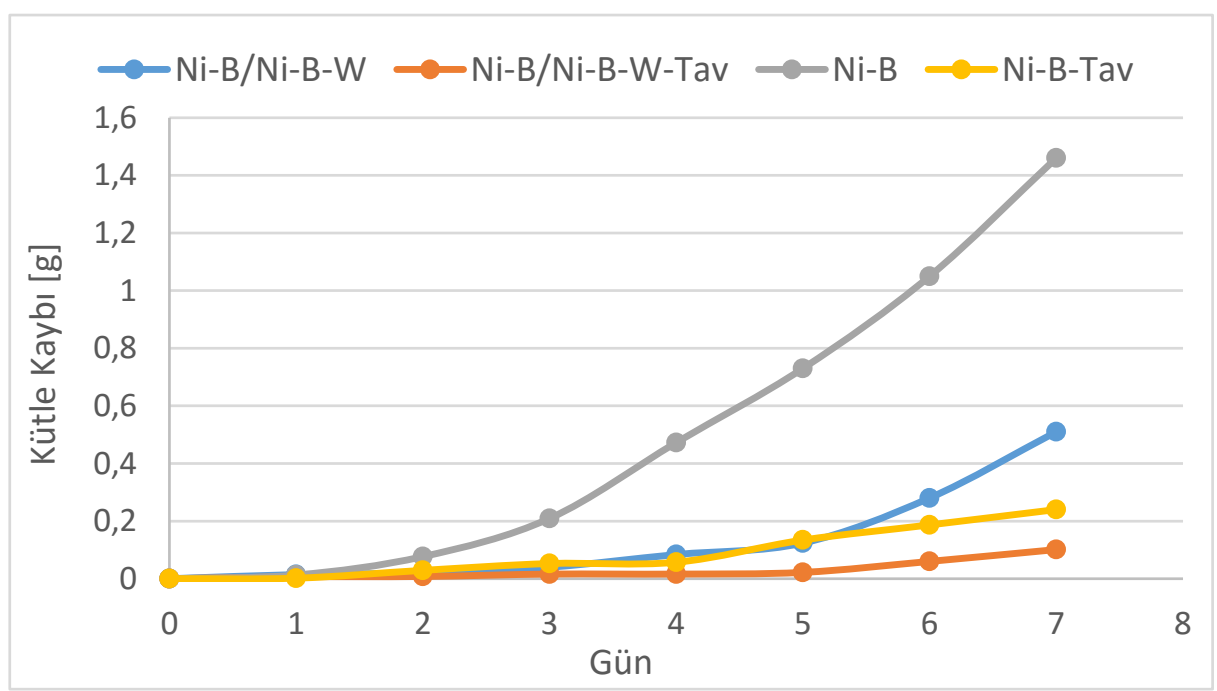

Şekil 5. Isıl işlem görmemiş ve görmüş Ni-B ve Ni-B/Ni-B-W dubleks kaplamalarının $\% 5 \mathrm{H}_{2} \mathrm{SO}_{4}$ çözeltide bekletmede sonucu kütle kaybı

\section{Potansiyometrik Polarizasyon}

Çeliğin, ısıl işlem görmemiş ve tavlanmış Ni-B ve Ni-B/Ni-B-W kaplamaların korozyon davranışlarını elektrokimyasal olarak tespit edebilmek için tafel polarizasyon eğrileri elde edilmiştir. Şekil 6 da çelik ile Ni-B/NiB-W dubleks kaplamalarının polarizasyon eğrileri, tablo 2 de ise \%3,5 sodyum klorid çözeltide gerçekleştirilen deneyler sonucu elde edilen korozyon potansiyel $\left(E_{k o r}\right)$ ve korozyon akım $\left(i_{\text {kor }}\right)$ değerleri görülmektedir. Şekil 6 ve tablo 2 den de görüldüğü gibi çeliğin korozyon potansiyel değeri $-601 \mathrm{mV}$ ve korozyon akımı iKor $23,08 \mu \mathrm{A} / \mathrm{cm}^{2}$ dir, tavlanmış Ni-B/Ni-B-W kaplamasının Ekor değeri $-271 \mathrm{mV}$ ve $i_{\text {kor }}$ değeri $0,48 \mu \mathrm{A} / \mathrm{cm}^{2}$ dir. Bu da dubleks kaplamanın çeliğe göre korozyon potansiyeli yaklaşık $300 \mathrm{mV}$ mertebesinde daha pozitif bir değere çektiğini göstermektedir. Şekil 7 de ise \%3,5 sodyum klorid çözeltide gerçekleştirilen polarizasyon deneyi sonucunda 1sıl işlem görmemiş Ni-B/Ni-B-W kaplamanın SEM yüzey morfolojisi görülmektedir. 


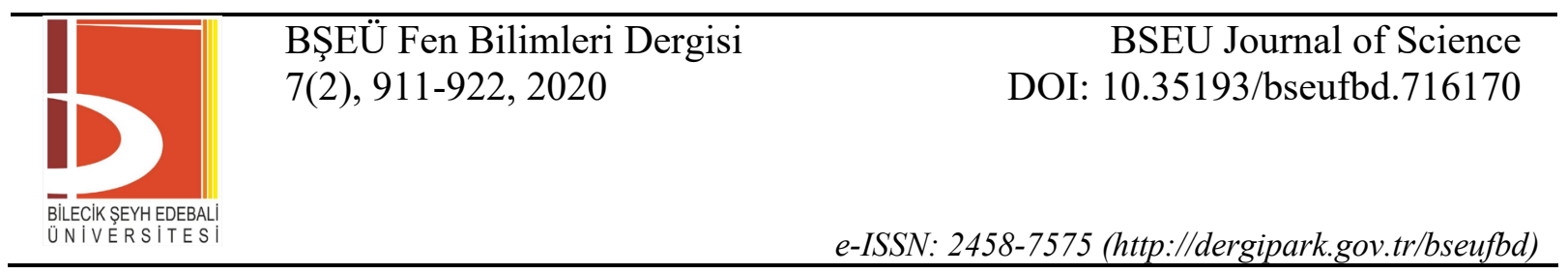

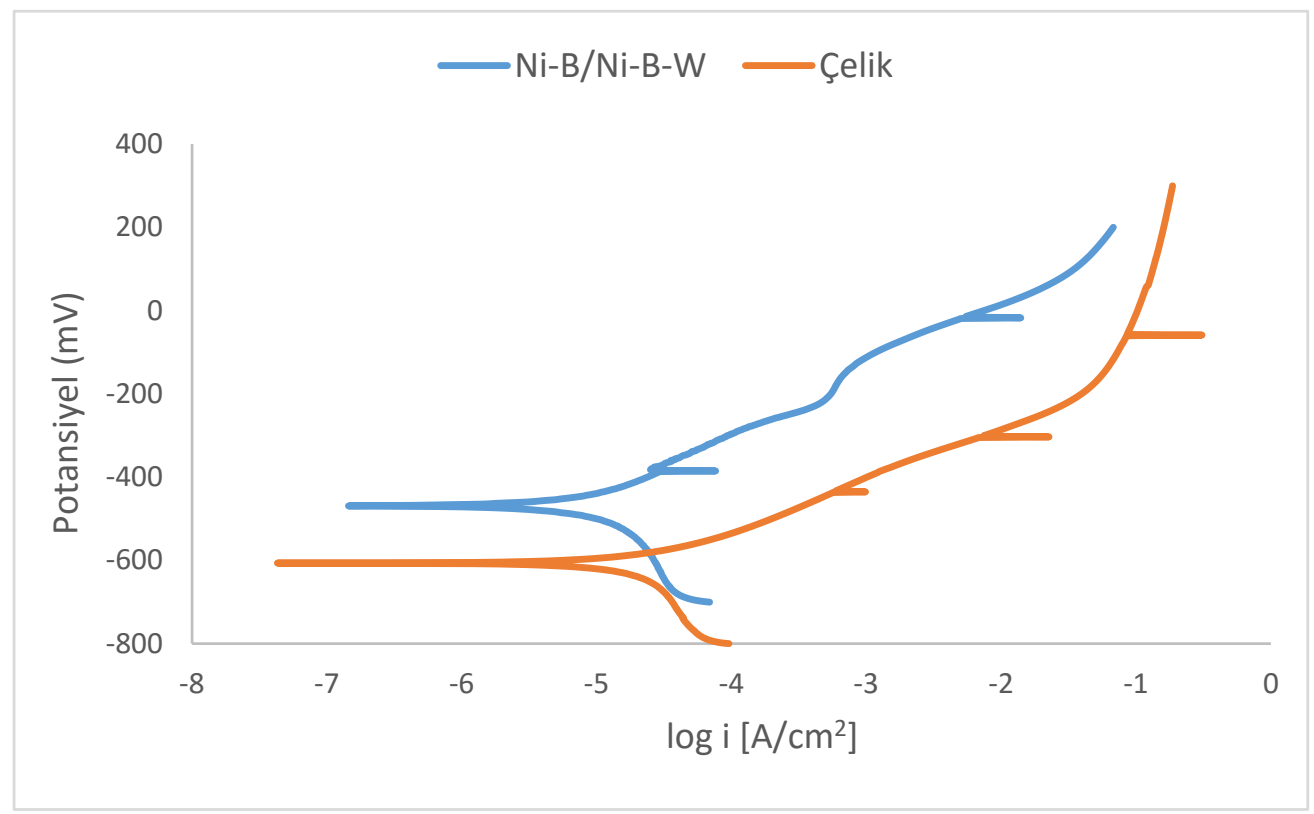

Şekil 6. Çelik malzemenin ve ısıl işlem görmemiş Ni-B/Ni-B-W kaplamasının anodik polarizasyon eğrileri

Tablo 2. Potansiyometrik polarizasyon testleri sonucu çelik ve 1 sıl işlem görmemiş Ni-B/Ni-B-W dubleks kaplamasının korozyon potansiyel $\left(\mathrm{E}_{\mathrm{kor}}\right)$ ve korozyon akımı (i $\left.\mathrm{i}_{\mathrm{kor}}\right)$ değerleri.

\begin{tabular}{|c|c|c|}
\hline Numune No & $\mathbf{E}_{\mathbf{k o r}}(\mathbf{m V})$ & $\mathbf{i}_{\mathbf{k o r}}\left(\boldsymbol{\mu \mathbf { A } / \mathbf { c m } ^ { 2 } )}\right.$ \\
\hline Steel & -601 & 23,08 \\
\hline Ni-B & -473 & 16,43 \\
\hline Ni-B tavlanmış & -280 & 1,43 \\
\hline Ni-B/Ni-B-W & -376 & 11,42 \\
\hline Ni-B/Ni-B-W tavlanmıș & -271 & 0,48 \\
\hline
\end{tabular}
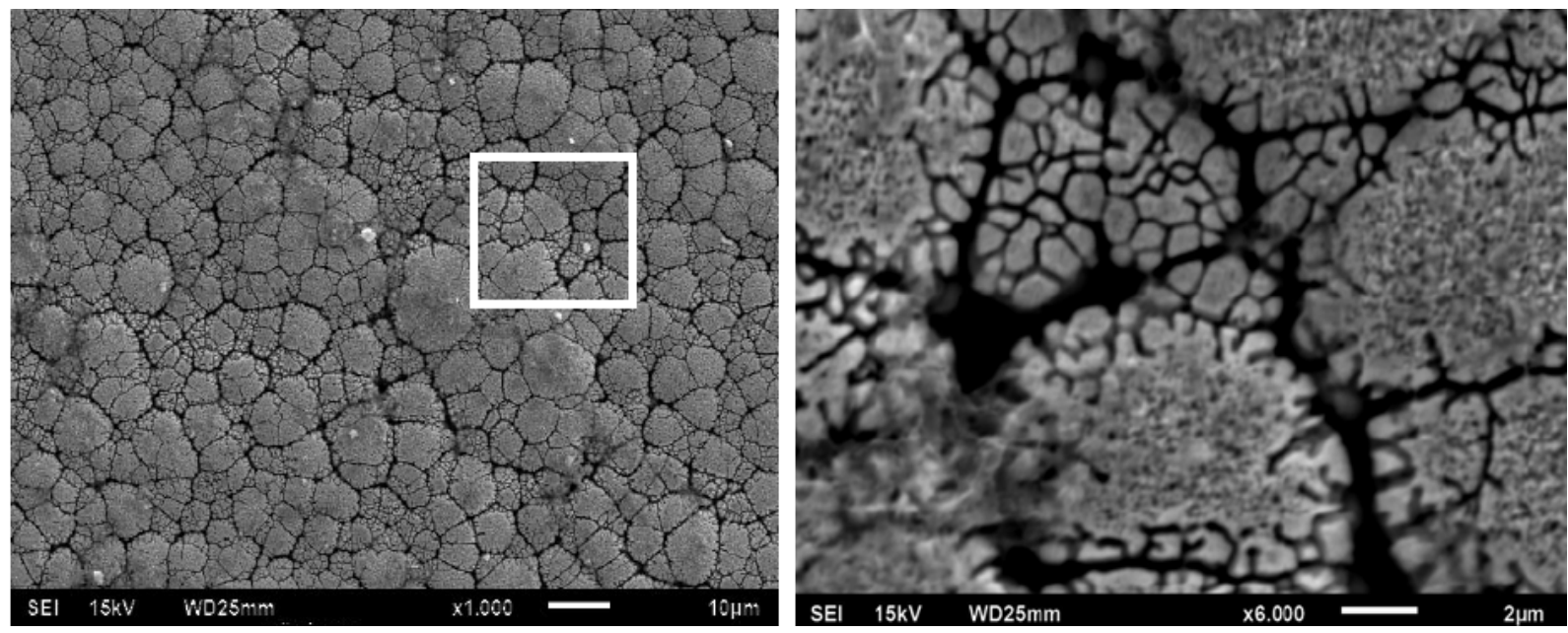

Şekil 7. \%3,5 sodyum klorid çözeltide gerçekleştirilen polarizasyon deneyi sonucunda Ni-B/Ni-B-W kaplamanın SEM yüzey morfolojisi 
Şekil 8 de 1 sıl işlem görmemiş ve görmüş Ni-B ve Ni-B/Ni-B-W dubleks kaplamalarının polarizasyon eğrileri, tablo 3 de ise \%3,5 sodyum klorid çözeltide gerçekleştirilen deneyler sonucu elde edilen korozyon potansiyel $\left(\mathrm{E}_{\mathrm{kor}}\right.$ ) ve korozyon akım ( $\left.\mathrm{i}_{\mathrm{kor}}\right)$ değerleri görülmektedir.

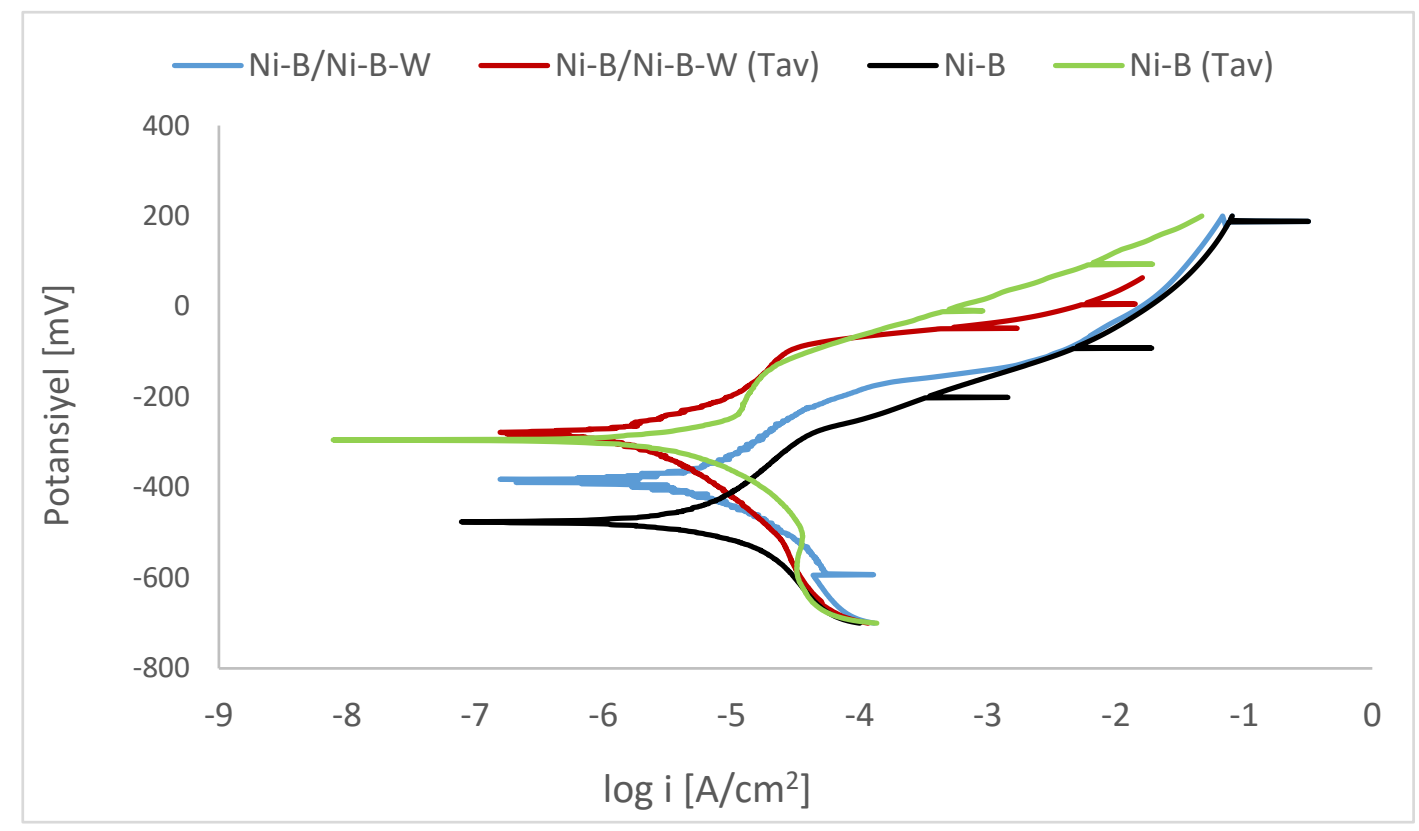

Şekil 8. Isıl işlem görmüş ve görmemiş Ni-B ve Ni-B/Ni-B-W kaplamalarının anodik polarizasyon eğrileri

Ni-B ve Ni-B/Ni-B-W dubleks kaplamalarının korozyon direncini tespit etmek için daldırma ve Potansiyometrik Polarizasyon deneyleri gerçekleştirilmiş̧ir. Korozyon deney sonuçları incelendiğinde, çeliğin korozyon direncinin en kötüsü olduğu görülmüştür. Isıl işlem görmemiş Ni-B/Ni-B-W kaplamasının korozyon direnci Ni-B kaplamaya göre, az da olsa, daha iyidir. Isıl işlemin uygulanması sonucu her iki kaplamanın da korozyon direnci artmıştır. Ancak Ni-B/Ni-B-W dubleks kaplamasında bu artış Ni-B kaplamaya göre daha fazladır. Belirtilen kaplamalar ve tavla işlemleri sonucu korozyon direncindeki artışın nedenlerinin araştırılması sonucu şu sonuçlara ulaşılmışıı;; Song [42] tarafından da belirtildiği gibi, akımsız nikel kaplamalar sonucu kaplamada artık çekme gerilmeleri oluşmaktadır. Bu gerilmelerin varlığı, korozyon oluşumunu hızlandırmaktadır. Isıl işlem sonrası ise kaplamanın içyapısı amorf yapıdan kristalik yapıya dönüşmektedir. Bu da mikrotanelerin ve tane sınırlarının oluşması demektir. Kaplama içindeki tungsten (W), isıl işlem esnasında oluşan bu tane sınırlarından hareket ederek yüzeye ulaşabilmekte ve yüzeyde koruyucu tungstenoksit tabakasını meydana getirmektedir. Bu tabaka kaplamanın korozyon direncini arttırmaktadır. Ayrıca ısıl işlem sonucu oluşan $\mathrm{Ni}_{2} \mathrm{~B}$ and $\mathrm{Ni}_{3} \mathrm{~B}$ çökeltileri de nikel fazı ile mikro-galvanik hücrelerin oluşmasına neden olmaktadır ki bu da korozyon direncine olumlu katkıda bulunmaktadır.

\section{SONUÇLAR}

Bu çalışmada çelik malzemenin yüzeyi, akımsız Ni-B ve Ni-B/Ni-B-W dubleks kaplama ile kaplanmıştır. Kaplamaların bir kısm $450^{\circ} \mathrm{C}$ de bir saat ısıl işleme tabi tutulmuştur. Isıl işlem görmemiş ve görmüş Ni-B ve NiB/Ni-B-W kaplamaların içyapı, yüzey morfolojisi ve kesit görüntüleri incelenmiştir. İnceleme sonucu Ni-B/Ni-BW kaplamasının da yüzeye çok iyi bir adezif bağ ile gözeneksiz bir şekilde bağlandığı görülmüştür. EDS analizleri sonucu kaplamada \%0,62 tungstenin (W) varlığı tespit edilmiştir. XRD analizleri sonucu Ni-B/Ni-B-W kaplamanın amorf yapıda olduğu, uygulanan ısıl işlem ile kaplamanın kristalleştiği ve $\mathrm{Ni}_{2} \mathrm{~B}$ and $\mathrm{Ni}_{3} \mathrm{~B}$ çökeltilerinin oluştuğu tespit edilmiştir. Isıl işlem görmemiş ve görmüş Ni-B/Ni-B-W kaplamaların korozif karakterini incelemek için daldırma ve Potansiyometrik Polarizasyon deneyleri gerçekleştirilmiştir. Deneyler sonucu her iki tür kaplamanın korozyon direncinin kaplanan malzeme olan çelikten daha yüksek olduğu görüssmüştür. Isıl işlem görmemiş Ni-B/Ni-B-W kaplamasının korozyon direnci Ni-B kaplamaya göre daha iyidir. Isıl işlemin 
uygulanması sonucu her iki kaplamanın da korozyon direnci artmıştır. Ancak Ni-B/Ni-B-W dubleks kaplamasında bu artış Ni-B kaplamaya göre daha fazladır. Kaplamaya tungstenin eklenmesi ile 1sıl işlem sonrası yüzeyde oluşturduğu koruyucu tungstenoksit tabakasından dolayı, kaplamanın korozyon direnci artırmıştır. Gelecekte bu çalışma, farklı tavlama sıcaklıkların Ni-B/Ni-B-W dubleks kaplamasına etkisini analiz etmek için geliştirilmesi düşünülmektedir.

\section{TEŞEKKÜR}

$\mathrm{Bu}$ çalışma İstanbul Teknik Üniversitesi MYL-36421 no.lu Bilimsel Araştırma Proje (BAP) ile desteklenmiştir.

\section{KAYNAKLAR}

[1] Mallory, G. O., Hajdu, J. B. (1990). Electroless Plating: Fundamantals and Applications. American Electroplaters and Surface Finishers Society, Florida, 1990.

[2] Sahoo, P., Das, S.K. (2011). Tribology of Electroless Nickel Coatings a Review. Material Design, 32, 17601775 .

[3] Riedel, W. Electroless Nickel Plating. (1991). ASM International Metals Park, Ohio, USA.

[4] Masoumi, F., Ghasemi, H. R., Ziaei, A. A., Shahriari, D. (2012). Tribological characterization of electroless $\mathrm{Ni}-10 \% \mathrm{P}$ coatings at elevated test temperature under dry conditions. International Journal of Advanced Manufacturing Technology, 62, 1063-1070.

[5] Bülbül, F. (2011). The Effects of Deposition Parameters on Surface Morphology and Crystallographic Orientation of Electroless Ni-B Coatings. Metallic Materials. 17, 67-75.

[6] Das, S.K., Sahoo, P. (2010). Wear Performance Optimization of Electroless Ni-B Coating Using Taguchi Design of Experiments, Tribology in industry, Volume 32.

[7] Correa, E., Zuleta, A.A., Guerra, L., Gomez, M.A., Castaño, J.G., Echeverría, F.,, Liu, H., Skeldon, P., Thompson, G.E. (2013). Tribological behaviour of electroless Ni-B coatings on magnesium and AZ91D alloy. Wear, 305, 115-123

[8] Palaniappa, M., Seshadri, S.K. (2008). Friction and wear behavior of electroless Ni-P and Ni-W-P alloy coatings. Wear, 265, 735-740.

[9] Yan, Y., Huo, Y., Sun, Z., Xu, Z. (2011). Preparation of Electroless Ni-P Composite Coating and Its Tribological Properties, Advanced Materials Research, 199-200, 696-699.

[10] Véronique, V., Abdoul-Fatah, K., Adeline, S., Fabienne, D. (2012). Tribological characterization of electroless nickel-boron coatings, Advanced Materials Research, 409, 808-813.

[11] He, M., Hu, W., Zhang, C., Weng, J., Shen, B., Wu, Y. (2012). Effect of Wear Conditions on Tribological Properties of Ni-P Coatings, Trans. Nonferrous Met. Soc. China, 22, 2586-2592.

[12] Nava, D., Hernandez, A.M., Manriquez, F., Meas, Y., Borges, R.O., Perez, J.J., Trejo, G. (2013). Effects of Heat Treatment on the Tribological and Corrosion Properties of Electrodeposited Ni-P Alloys, International Journal of Electrochemical Science, 8, 2670-2681.

[13] Narayanan, T.S.N., Baskaran, I., Krishnaveni, K., Parthiban, S. (2006). Deposition of Electroless Ni-P Graded Coatings and Evaluation of Their Corrosion Resistance. Surface and Coatings Technology, 200, 3438-3445.

[14] Zhang, W.X., He, J.G., Jiang, Z.H., Jiang, Q., Lian, J.S. (2007). Electroless Ni-P layer with a chromium-free pretreatment on AZ91D magnesium alloy. Surface Coating Technology, 201, 4594-4600. 
[15] Hu, X., Jiang, P., Wan, J., Xu, Y. Xiaojun, (2009). Study of corrosion and friction reduction of electroless $\mathrm{Ni}-\mathrm{P}$ coating with molybdenum disulfide nanoparticles. Journal of Coating Technology Research, 6 (2) 275281.

[16] Anik, M., Körpe, E., Sen, E. (2008). Effect of Coating Bath Composition on the Properties of Electroless Nickel-Boron Films, Surface Coating Technology, 202, 1718-1727.

[17] Hamid, Z.A., Hassan, H.B., Attyia, A.M. (2010). Influence of Deposition Temperature and Heat Treatment on the Performance of Electroless Ni- B Films, Surface Coating Technology, 205, 2348-2354.

[18] Oraon, B., Majundar, G., Ghjosh, B. (2008). Improving Hardness of Electroless Ni-B Coatings Using Optimized Deposition Conditions and Annealing, Material Design, 29, 1412-1418.

[19] Delaunois, F., Lienard, P. (2002). Heat treatments for electroless nickel-boron plating on aluminium alloys. Surface and Coatings Technology, 160, 239-248.

[20] Serin, I., Göksenli, A. (2013). Effect of Annealing Temperature on Hardness and Wear Resistance of Electroless Ni-B-Mo Coatings, 1st International Conference on Surface Engineering, 2013 Busan, Korea.

[21] Narayanan T., Stephan A., S. Guruskanthan S., Electroless Ni-Co-B Ternary Alloy Deposits: Preparation and Characteristics, Surf. Coat. Technol., , 179, p 56-62.

[22] Szczygiel, B., Turkiewicz, A., Serafinczul, J. (2004). Surface morphology and structure of Ni-P, Ni-P-ZrO2, $\mathrm{Ni}-\mathrm{W}-\mathrm{P}, \mathrm{Ni}-\mathrm{W}-\mathrm{P}-\mathrm{ZrO} 2$ coatings deposited by electroless method. Surface Coating Technology, 202, 19041910.

[23] Kaya, B., Gülmez, T., Demirkol, M. (2008). Preparation and Properties of Electroless Ni-B and Ni-B Nanocomposite Coatings Proceedings of the World Congress on Engineering and Computer Science 2008 WCECS 2008, October 22 - 24, San Francisco, USA.

[24] Agarwala, R.C., Agarwala, V. (2003). Electroless Alloy/Composite Coatings: A Review. Sadhana, 28, 475493.

[25] Serin, I.S., Göksenli, A., Yüksel, B., Yildiz, R.A. (2015). Effect of Annealing Temperature on the Corrosion Resistance of Electroless Ni-B-Mo Coatings, Journal of Materials Engineering and Performance, 24, 30323037.

[26] Ziywan, S., Deping, W., Zhimin, D. (2006). Nanocrystalline Ni-B Coating Surface Strengthening Pure Copper. Applied Surface Science, 253, 1051-1054.

[27] Zhao, C., Yao, Y. (2014). Preparation and Mechanical Properties of Electroless Nickel-Phosphorus-Tungsten Carbide Nanocomposite Coatings, Journal of Material Engineering \& Performance, 23, 193-197.

[28] Sharma, A., Singh, A.K. (2013). Electroless Ni-P and Ni-P-A12O3 Nanocomposite Coatings and their Corrosion and Wear Resistance, Journal of Material Engineering \& Performance, 22, 176-183.

[29] Karthikeyan, S., Srinivasan, K.N., Vasudevan, T., John, S., Gopalan, A., Kalaignan, S. (2001). Characterisation of Nickel Phosphorus Silicon Carbide Composite Coatings, Bullettin of Electrochemie., 17, $127-130$.

[30] Bai, Y., Chou, Y.H., Chao, C.L., Lee, S.J., Ger, M.D. (2008). Evaluation of Corrosion Resistance of Electroless Ni-P/Ni-W-P Double Layer Coatings on 6061 Aluminium Alloy, Journal of Power Source, 183, 174-181.

[31] Chen, X., Li, G., Lian, J. (2008). Deposition of electroless Ni-P/Ni-W-P duplex coatings on AZ91D magnesium alloy, Transaction of Nonferrous Metals Society China, 18, 323-328. 
[32] Zhang, Z.H., Jiang, G.Y., Li, Q., Jiang, J.S. (2008). Electroless Ni-P/Ni-B duplex coatings for improving the hardness and the corrosion resistance of AZ91D magnesium alloy,. Applied Surface Science, 254, 49494955 .

[33] Narayanan, T.S.N., Krishnaveni, K., Seshadri, S.K. (2003). Electroless Ni-P/Ni-B duplex coatings: preparation and evaluation of microhardness, wear and corrosion resistance, Materials Chemistry and Physics 82, 771-779.

[34] Novak, M., Vojitech, D., Vitu, T. (2010). Influence of heat treatment on tribological properties of electroless $\mathrm{Ni}-\mathrm{P}$ and Ni-P-Al $\mathrm{O}_{3}$ coatings on Al-Si casting alloys. Applied Surface Science, 256, 2956-2960.

[35] Contreras, A., Leon, C., Jimenez, O., Sosa, R., Perez, R. (2006). Electrolchemical behior and microstructural characterization of $1026 \mathrm{Ni}-\mathrm{B}$ coated steel. Applied Surface Science, 253, 592-599.

[36] Steffani, P., Dini, J.W., Groza, J.R., Palazoglu, A. (1997). Electrodeposition and Corrosion Resistance of NiB-W Coatings,. Journal of Material Engineering Performance, 6, 413-416.

[37] Drovosekov, A., Ivanov, M., Krutskikh, V., Lubnin, E., Polukarov, Y. (2005). Chemically Deposited Ni-WB Coatings: Composition, Structure, and Properties, Prot. Metals, 41, 55-62.

[38] Zhang, W.X., Huang, N., He, J.G., Jiang, Z.H., Jiang, Q., Lian, J.S. (2007). Electroless deposition of Ni-WP coating on AZ91D magnesium alloy. Applied Surface Science, 253, 5116-5121.

[39] Aydeniz, A.İ., Göksenli, A., Dil G., Muhaffel, F., Calli, Ç., Yüksel, B. (2013). Electroless Ni-B-W Coatings for Improving Hardness, Wear and Corrosion Resistance. Materials and technology, 47, 803-806.

[40] Chen, X, Li G, Lian J, (2008). Deposition of Electroless Ni-p/Ni-W-P Dublex Coatings on AZ 91D Magnesium Alloy. Trans. Nonferrous Metarials Society China, 18, 323-328.

[41] Drovosekov, A., Ivanov, M., Krutskikh, V., Lubnin, E., Polukarov, Y. (2005). Chemically Deposited Ni-WB Coatings: Composition, Structure, and Properties. Prot. Metals, 41, 55-62.

[42] Song, J.Y., Yu, J. (2002). Residual stress measurements in electroless plated Ni-P films. Thin Solid Films, $415,167-172$. 